\section{SOI: 1.1/TAS DOI: 10.15863/TAS International Scientific Journal Theoretical \& Applied Science}

\section{Gulvira Korkemova Azimkhanova} lecturer of Propedeutics and Internal disease department International Kazakh-Turkish University by name Yassavi, Kazakhstan gulvira1202@mail.ru

p-ISSN: 2308-4944 (print) e-ISSN: 2409-0085 (online)

Year: $2018 \quad$ Issue: $03 \quad$ Volume: 59

Published: $30.03 .2018 \quad$ http://T-Science.org

SECTION 20. Medicine.

\title{
PREVALENCE OF ARTHROSIS AMONG WOMEN OVER 40 YEARS OF LIVING IN THE TURKESTAN REGION
}

Abstract: This article presents a study of the prevalence of arthrosis in women after the age of 40 living in the Turkestan region.

Key words: arthrosis, frequency of occurrence, women.

Language: Russian

Citation: Azimkhanova GK (2018) PREVALENCE OF ARTHROSIS AMONG WOMEN OVER 40 YEARS

OF LIVING IN THE TURKESTAN REGION. ISJ Theoretical \& Applied Science, 03 (59): 277-280.

Soi: http://s-o-i.org/1.1/TAS-03-59-47 Doi: crossef https://dx.doi.org/10.15863/TAS.2018.03.59.47

\section{РАСПРОСТРАНЕННОСТЬ АРТРОЗА СРЕДИ ЖЕНЩИН СТАРШЕ 40 ЛЕТ ПРОЖИВАЮЩИХ В ТУРКЕСТАНСКОМ РЕГИОНЕ}

Аннотация: В данной статье представлено изучение распространенности артроза среди женщин 8 возрасте после 40 лет, проживаюших в Туркестанском регионе.

Ключевые слова: артроз, частота встречаемости, женщины.

\section{Введение.}

Артроз заболевание которое, начинается с изменений хрящевой ткани. Хрящ в суставах выполняет две основные функции: обеспечение движения кости относительно друг друга и уменьшение веса кости во время движения. Но это касается здорового хряща. Если в нем начинается измения структуры, движения костей намного затрудняются, даже при незначительной физической нагрузке. В результате также страдают мышцы и структуры, окружающие кость и суставную капсулу. Если хрящ подвергается таким изменениям, он не может быть полностью восстановлен. Современная медицина не обладает методами полностью восстанавливающие хрющевую ткань, но имеются достаточно лекарственных средств, которые останавливают дальнейшую деструкцию хряща и уменьшают боль [1].

Истинная причина артрозов до сих пор неизвестна, но есть несколько факторов, которые могут увеличить риск развития этого состояния:

- Возраст старше 40 лет, некоторые исследователи считают, что «остеоартроз является естественным результатом общего износа тела».
- Пол - остеоартрозом чаще страдают женщины, чем мужчины.

- Ожирение - лица с избыточным весом находятся под высоким риском.

- Наличие травмы в анамнезе - которое способствует развитию остеоартроза (например, когда речь идет о спорте). Наряду с этим большое значение имеет проведенные операции на суставах.

- Наличие таких заболеваний, как ревматоидный артрит, или подагра в костномышечной системе - лица с указанными заболеваниями имеют тенденцию к остеоартрозу.

- Профессиональные вредности - имеются данные, что повышенная мобильность в профессиональной деятельности также является риском развития остеоартроза у этих лиц.

- Генетическая предрасположенность болезнь, известная как артроз обычно часто затрагивает всех членов семьи [1,2].

Симптомы остеоартроза развиваются постепенно в ходе развития болезни. Анальгетики, стероиды, физиотерапия и некоторые дополнительные терапевтические 
препараты могут помочь облегчить состояние пациента [3].

Остеоартроз не имеет четкого набора симптомов, что в определенной мере затрудняет диагностику данного заболевания. Некоторые пациенты не испытывают никаких симптомов болезни, у других проявления недуга может появится с первых же дней в виде неспособности двигаться.

Симптомы остеоартроза:

- Боль в пояснице

- Боль в суставах

- Боль в колене

- Воспаление сустава

- Боль в паху

- Припухлость пораженного сустава

- Боль в ночное время

- Деформация сустава

Остеоартроз может постепенно прогрессироваться, а при этом симптомы заболевания незначительно возрастают. Причина боли при остеоартрозе в основном кроется в реактивном синовите которое характеризуется сокращением мышц которые расположены рядом с пораженным суставом. Реактивный синовит характеризуется «стартовыми болями» которые появляются при первых шагов. В дальнейшем боль может исчезать а вновь ее появление встречается при продолжении физических нагрузок на пораженный сустав. Появление начальных болей в пораженном суставе появляются в результате трения хрящей суставов $[4,5]$.

Каждая женщина входит в естественную фазу репродуктивных аномалий репродуктивной функций в период от 45 до 55 лет. Этот этап, называемый менопаузой, оказывает значительное влияние на качество жизни женщины. Нестабильный эмоциональный фон, беспокойство, боль в животе, головная боль, боль в костях и мышцах - неизбежный спутник менопаузы. Важно знать, почему менопауза вызывает изменения в костях и суставах. Во время менопаузы яичники прекращают функционировать, которые являются производством основных гормонов эстрогена и прогестерона. Гормон эстроген играет важную роль в жизни женщины. Таким образом, эстроген снижает активность клеток, которые поглощают костную ткань (остеокласты). менопауза приводит к отсутствию половых гормонов и дальнейшему разрушению суставов. Отсутствие эстрогена в женском теле оживляет разрушительную активность остеокластов в суставах, разрушает всасывание минеральных веществ и обмен кальция в костях. Костная ткань является хрупкой. Если эта тенденция очевидна, снижение прочности кости может привести к развитию остеоартроза и остеопороза. Дефекты и деформации костной ткани могут не отмечаться в течение длительного времени [6,7].

В то время как остеоартроз является дегенеративным заболеванием суставов, которое может вызвать потерю хряща и морфологическое повреждение других тканей суставов, более тонкие биохимические изменения происходят на самых ранних стадиях прогрессирования остеоартроза. Содержание воды в здоровом хряще сбалансировано сжимающей силой, вытесняющей воду, гидростатическим и осмотическим давлением, втягивающим воду [8]. Коллагеновые волокна оказывают сжимающее усилие, тогда как эффект Гиббса-Доннана и протеогликаны хряща создают осмотическое давление, которое имеет тенденцию втягивать воду [9].

Однако при развитии остеоартроза коллагеновая матрица становится более дезорганизованной и снижается содержание протеогликана в хряще. Распад коллагеновых волокон приводит к увеличению содержания воды [10]. Это увеличение происходит потому, что в то время как существует полная потеря протеогликанов (и, следовательно, снижение осмотического напряжения), он перевешивается потерей коллагена [11]. Без защитных эффектов протеогликанов коллагеновые волокна хряща могут стать восприимчивыми к деградации и тем самым усугубить дегенерацию.

Другие структуры внутри сустава также могут быть затронуты [12]. Связки в суставе становятся утолщенными и фиброзными, мениски могут стать поврежденными и изнашиваться [13]. Новые костяные наросты, называемые «шпорами» или остеофитами, могут образовываться на краях суставов, возможно, в попытке улучшить конгруэнтность суставных поверхностей хряща в отсутствие менисков. Объем субхондральной кости увеличивается и становится менее минерализованным (гипоминерализация) [14]. Все эти изменения могут вызвать проблемы. Боль в остеоартритном суставе была связана с утолщенным синовием [15] и субхондральными костями [16].

Женщины часто не обращают внимания или долго терпят боль в суставах и мышцах. По этой причине они не связывают аномалии ног и общая усталость с серьезными заболеваниями костномышечной системы. Тем не менее, гормональная реорганизация женского организма заслуживает внимания. Первым признаком дефицита кальция являются мышечные боли. Эта негативная тенденция начинает разрушать костную ткань. Наряду с кульминацией изменения в хряще влияют на возраст хряща. Среди них наблюдается замедление метаболизма и снижение уровня коллагена в организме. Весь набор этих причин 


\begin{tabular}{|c|c|c|c|c|c|c|}
\hline Impact Factor: & $\begin{array}{l}\text { ISRA (India) } \\
\text { ISI (Dubai, UAE } \\
\text { GIF (Australia) } \\
\text { JIF }\end{array}$ & $\begin{array}{l}=1.344 \\
=0.829 \\
=0.564 \\
=1.500\end{array}$ & $\begin{array}{l}\text { SIS (USA) } \\
\text { PИНЦ (Russia) } \\
\text { ESJI (KZ) } \\
\text { SJIF (Morocco) }\end{array}$ & $\begin{array}{l}=0.912 \\
=0.207 \\
=4.102 \\
=2.031\end{array}$ & $\begin{array}{l}\text { ICV (Poland) } \\
\text { PIF (India) } \\
\text { IBI (India) }\end{array}$ & $\begin{array}{l}=6.630 \\
=1.940 \\
=4.260\end{array}$ \\
\hline
\end{tabular}

является одной из основных причин артрозиса для женщин в возрасте старше 40 лет $[17,18]$.

Целью исследования является определение количества зарегистрированных женщин с артрозом в Туркестанском регионе в период 2012-2017 гг. и частоты артроза у женщин старше 40 лет.

Материал и методы исследования: 125 пациентов с остеоартрозом были зарегистрированы в Туркестанской городской больнице у ревматологов в 2012-2017 годы. Среди 116 пациентов 9 пациентов мужского пола.

Результаты исследования. В 2012 году 16 пациентов, в том числе 2 пациента в возрасте 4050 лет, 8 пациентов в возрасте 50-60 лет, шесть пациентов старше 60 лет.

\section{Распространенность артроза в зависимости от возраста.}

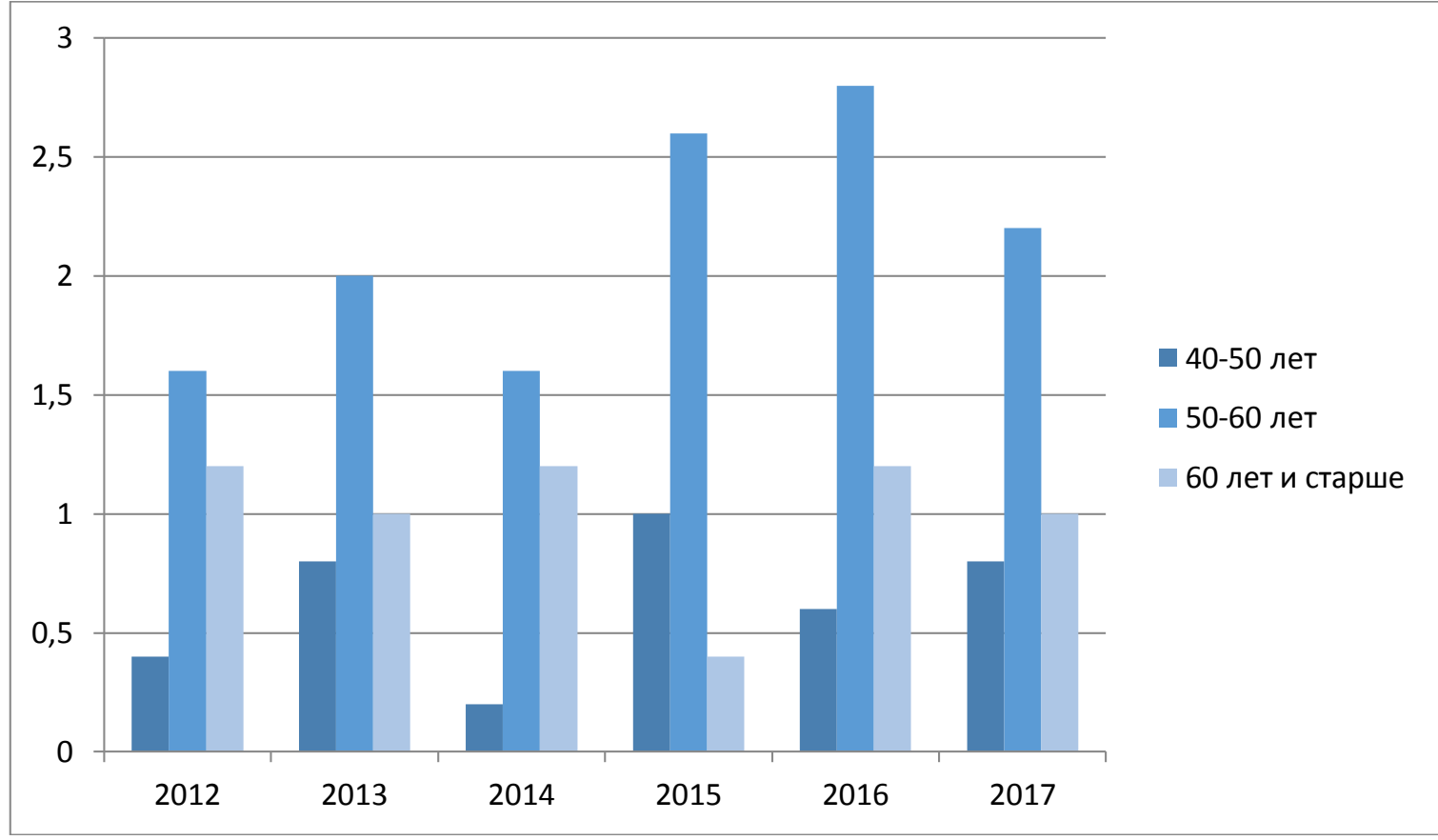

В 2013 году было 19 пациентов, в том числе 4 пациента в возрасте 40-50 лет, 10 пациентов в возрасте 50-60 лет и 5 пациентов старше 60 лет.

В 2014 году было зарегистрировано 15 пациентов, в том числе 1 пациент в возрасте от 40 до 50 лет, 8 пациентов в возрасте 50-60 лет и шесть пациентов старше 60 лет.

В 2015 году 20 пациентов, в том числе 5 пациентов в возрасте 40-50 лет, 13 пациентов в возрасте 50-60 лет, два пациента старше 60 лет.

В 2016 году 25 пациентов, в том числе 3 пациента в возрасте 40-50 лет, шестнадцать пациентов в возрасте 50-60 лет, шесть пациентов старше 60 лет.

В 2017 году было зарегистрировано 21 пациент, в том числе 4 пациента в возрасте 40-50 лет, 12 пациентов в возрасте 50-60 лет и 5 пациентов старше 60 лет.

\section{Вывод:}

Было выявлено что возраст старше 40 лет, как правило, связан с артрозом из-за наступления менопаузы, отсутствия половых гормонов в организме, необратимых изменений в суставе. Именно по этой причине у женщин чаще встречаются суставные и костные заболевания по сравнению с мужчинами. Результаты данного исследования показали, что женщины в возрасте 50-60 лет имеют высокий уровень заболеваемости, вследствие того, что женщины старше 40 лет, которые часто упускаются, не уделяя большого внимания изменениям в организме. По этой причине преобладает число пациентов старше 40 лет. 


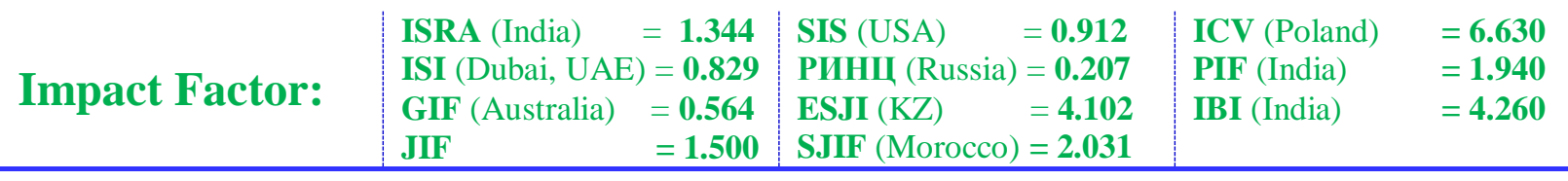

\section{References:}

1. Karkabaeva A.V. (2011) «Vnutrennie bolezni» Almaty. 2011 god. - «Evero» - p.342.

2. Nasonov E.L (2015) « Revmatologiya». Moskva, 2015 god. GEOTAR- Media. -p.211.

3. Creamer P., Goldberg M.C. (1997) Osteoarthritis // The Lancet. — 1997. — Vol. 350. - p. 503-509.

4. Altman R., Alarcon G., Appelrouth D. et al. (1991) The American College of Rheumatology criteria for classification and reporting of osteoarthritis of the hip // Arthritis Rheum. 1991. - Vol. 34. - p. 505-514.

5. Kovalenko V.N., Bortkevich O.P. (2003) Osteoartroz. - K.: Moryun, 2003. - 448 p.

6. Saito T, Kawaguchi H. (2011) Transcriptional regulation of osteoarthritis // Clin. Calcium. 2011. - Vol. 21, № 6. -p. 853-859.

7. Watson P.J., Hall L.D. (1996) Degenerative joint disease in the guinea pig. Use of magnetic resonance imaging to monitor progression ofbone pathology // Arthritis Rheum. - 1996. - Vol. 39, № 8. - p. 1327-1337.

8. Sanchez-Adams J, Leddy HA, McNulty AL, O'Conor CJ, Guilak F (2014) "The mechanobiology of articular cartilage: bearing the burden of osteoarthritis". Curr Rheumatol Rep. 16 (10): 451.

9. Maroudas AI (1976). "Balance between swelling pressure and collagen tension in normal and degenerate cartilage". Nature. 260 (5554): 808-09.

10. Bollet AJ, Nance JL (1966). "Biochemical Findings in Normal and Osteoarthritic Articular Cartilage. II. Chondroitin Sulfate Concentration and Chain Length, Water, and Ash Content". J. Clin. Invest. 45 (7): 1170.

11. Brocklehurst R, Bayliss MT, Maroudas A, Coysh HL, Freeman MA, Revell PA, Ali SY
(1984). "The composition of normal and osteoarthritic articular cartilage from human knee joints. With special reference to unicompartmental replacement and osteotomy of the knee". J Bone Joint Surg Am. 66 (1): 95106.

12. Chou MC, Tsai PH, Huang GS, Lee HS, Lee $\mathrm{CH}$, Lin MH, Lin CY, Chung HW (2009). "Correlation between the MR T2 value at $4.7 \mathrm{~T}$ and relative water content in articular cartilage in experimental osteoarthritis induced by ACL transection". Osteoarthr. Cartil. 17(4): 441-47.

13. Grushko G, Schneiderman R, Maroudas A (1989). "Some biochemical and biophysical parameters for the study of the pathogenesis of osteoarthritis: a comparison between the processes of ageing and degeneration in human hip cartilage". Connect. Tissue Res. 19 (2-4): 149-76.

14. Mankin HJ, Thrasher AZ (1975). "Water content and binding in normal and osteoarthritic human cartilage". J Bone Joint Surg Am. 57 (1): 76-80.

15. Venn M, Maroudas A (1977). "Chemical composition and swelling of normal and osteoarthrotic femoral head cartilage. I. Chemical composition". Ann. Rheum. Dis. 36 (2): 121-29.

16. Madry H, Luyten FP, Facchini A (2012). "Biological aspects of early osteoarthritis". Knee Surg. Sports Traumatol. Arthrosc. 20 (3): 407-22.

17. Englund M, Roemer FW, Hayashi D, Crema MD, Guermazi A (2012). "Meniscus pathology, osteoarthritis and the treatment controversy". Nat. Rev. Rheumatol. 8 (7): 412-19. 